Volume 9, No.5, September - October 2020

International Journal of Advanced Trends in Computer Science and Engineering

Available Online at http://www.warse.org/IJATCSE/static/pdf/file/ijatcse225952020.pdf

https://doi.org/10.30534/ijatcse/2020/225952020

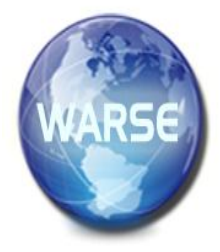

\title{
Numerical Study of Salt-Transfer Process in Soils
}

\author{
Sabur Aminov ${ }^{1}$, Narzulla Rajabov ${ }^{2}$, Temur Azamov ${ }^{3}$, Zafar Ravshanov ${ }^{3}$ \\ ${ }^{1}$ Tashkent State Agrarian University, Uzbekistan, sabur1088@mail.ru \\ ${ }^{2}$ Samarkand State Architecture-Building Institute, Uzbekistan, atn7772@gmail.com \\ ${ }^{3}$ Tashkent University of Information Technology, Uzbekistan, ravshanzade-09@ mail.ru
}

\begin{abstract}
Urgent problems related to the solution of salt-transfer problems in soil are considered in the paper. It is devoted to numerical modeling of salt transfer and diffusion process in soils. In modeling the total porosity of soil is divided by "through" and "dead-end" fraction of pores with corresponding solution strength. A brief review of scientific publications covering this problem is given. To study and predict the process of harmful substances spread, a mathematical model and numerical algorithm were developed to conduct a computer experiment. The solution to this problem was obtained using a method based on the use of quadrature formulas in combination with the differential sweep method for a system of ordinary differential equations of the second order with arbitrary linear boundary conditions. To test the proposed approach of numerical modeling, a specific problem was solved and the results were presented in tabular form and compared with exact solutions.
\end{abstract}

Key words : mass transfer, water mineralization, soil degradation, ecological engineering, numerical modeling.

\section{INTRODUCTION}

The analysis of the process study of water-salt-transfer in soil showed that crop yields can be obtained for several years when irrigated with water salinity of up to $15 \mathrm{~g} / \mathrm{l}$. Relative good reclamation state of lands irrigated by mineralized waters is temporary (for 2-3 years). The long-term irrigation leads in many cases to a serious consequence, manifested not so much in the form of salt toxic effect, but in the form of dramatic changes in soil physicochemical properties, an increase in alkalinity, and deterioration of water-physical properties of soils as a result of shale and silt formation.

Based on the foregoing, the study and adoption of managerial decisions on the process of water-salt-transfer in soil is an urgent problem in order to maintain the state of soils fit for growing agricultural products.
One of the most effective tools for predicting and monitoring soil state is a mathematical tool: a model-numerical algorithm and software packages that can be used to conduct a calculating experiment (CE) on a computer, setting the basic hydrochemical and hydrodynamic parameters of soil. To solve the above mentioned problem, research was carried out and significant results of applied and fundamental nature were obtained.

In particular, in [1], an actual problem associated with the process of water and salt transfer in soil was solved, and a review of scientific papers devoted to various aspects and mathematical support of the object under study was given. To conduct a comprehensive study, a mathematical model was proposed taking into account the colmatage of soil pores with fine particles over time; changes in soil permeability coefficient, water loss and filtration coefficient; changes in initial porosity and porosity of the settled mass; an effective numerical algorithm based on the Samarsky-Fryazinov vector scheme with a second order of approximation of differential operators to finite difference one was also proposed. To derive a mathematical model of salt transfer it was assumed that the pressure gradient in the channel is constant and equal to atmospheric pressure.

In [2], hydrodynamic and hydraulic models of water runoff in wetlands were proposed, they allowed describing the processes of filtration and surface runoff with varying degrees of detail and accuracy. Based on the models of salt transfer by interacting filtration and channel flows, the issues of modeling the quality of groundwater and surface water were considered.

A solution to the problem associated with the process of filtration and dehydration of liquid and ionic solutions from gel particles and heavy ionic compounds was considered in [3]. This process is implemented in the preparation and purification of chemical solutions, drinking water, pharmaceuticals, liquid fuels, common use products, etc. For the analysis, research, determination of the main parameters of technological process and operating modes of filter units and to support the adoption of management decisions a 
mathematical model was developed. Using the developed model, a series of computational experiments on a computer was carried out.

A mathematical model was developed in [4], to predict the groundwater levels in two-layer formations. In mathematical modeling of geofiltration process, a two-layer medium was considered; it consisted of two layers: soil (with low throughput capacity) and water.

The salt solution in soil can have two physical states: in the form of a solution firmly bound by molecular forces to particles surfaces, and in the form of a free solution occupying the space inside the pore cavities. It was shown in [5] that the assessment of the washing process as a process of displacing the salt solution in soil with washing water is valid for structureless, dusty and non-saline soils. On the basis of soil washing experiments, it was found that the removal of salts from previously wetted soil is reduced. This is due to the fact that during capillary wetting, salt efflorescences gradually dissolve and are absorbed into the unit together with water.

The motion of salt and water in soil is a complex physical and chemical process. Along with the displacement of a free solution by diffusion transfer of salts, dissolution of salts of solid phase, a salt exchange takes place between the free pore solution and intra-unit moisture [6-9]. The three-parameter model distinguishes between pore solutions located in "dead-end" pores and "through" pores. In the total porosity m of soil, the fraction of "through" pores $\mathrm{k}$ with the solution content $\mathrm{C}$ and the fraction of "dead-end" pores (1-k) with the concentration of solution $\mathrm{N}$ are distinguished. "Through" pores, which are active in filtration, exchange salts with "dead ends" pores.

Denote the rate of macro-transfer in "through" pores by $\theta$, and the coefficient of convective diffusion, referred to the surface unit of "through" pores by $D$.

\section{PROBLEM STATEMENT}

Consider the following mathematical model of salt transfer problem in soil on reclaimed lands [10]:

$$
\left\{\begin{array}{l}
k \frac{\partial C}{\partial t}+\theta k \frac{\partial C}{\partial x}+(1-k) \alpha(C-N)=D k \frac{\partial^{2} C}{\partial x^{2}} \\
\frac{\partial N}{\partial t}=\beta(C-N),
\end{array}\right.
$$

where $C$ and $N$ are the salt content in "through" and "dead-end" pores, respectively $(\mathrm{g} / \mathrm{l}) ; \beta$ - the parameter characterizing the intensity of exchange between the components $C$ and $N$ (1/day); $\alpha$ - the parameter characterizing the salt ventilation in active and stagnant zones, and considering the sorption effects in "through" pores (at $\alpha \neq \beta$ ) (1/day).

Various solutions of system (1) are possible, for example, under the following initial and boundary conditions:

$\left\{\begin{array}{lll}C=\tilde{C}_{0} & \text { at } & t=0 \\ N=\tilde{N}_{0} & \text { at } & t=0\end{array}\right.$

$\left\{\begin{array}{lll}C=C_{n} & \text { at } & x=0 ; \\ \frac{d C}{d x}=0 & \text { at } & x=L .\end{array}\right.$

$C_{n}$ is the concentration of wash water.

\section{SOLUTION METHOD}

The method for solving problem (1) - (3) is based on the use of quadrature formulas in combination with the differential sweep method [10-13].

Introducing the following dimensionless quantities into (1) (3)

$$
\begin{aligned}
& \bar{x}=\frac{x}{L} ; \bar{t}=\frac{D}{L^{2}} t ; \bar{C}=\frac{C}{C_{x}} ; \bar{N}=\frac{N}{C_{x}} ; \\
& \tilde{C}_{01}=\frac{\tilde{C}_{0}}{C_{x}} ; \bar{C}_{n}=\frac{C_{n}}{C_{x}} ; \bar{N}_{01}=\frac{\tilde{N}_{0}}{C_{x}},
\end{aligned}
$$

while maintaining the same notation and accepting

$\mu_{1}=\frac{\theta L}{D} ; \quad \mu_{2}=\frac{L^{2} \alpha}{D k} ; \quad \mu_{3}=\frac{L^{2} \beta}{D}$

we obtain

$\left\{\begin{array}{l}\frac{\partial C}{\partial t}+\mu_{1} \frac{\partial C}{\partial x}(1-k)(C-N)=\frac{\partial^{2} C}{\partial x^{2}} \\ \frac{\partial N}{\partial t}=\mu_{3}(C-N) .\end{array}\right.$

Assuming $\quad t_{m}=(m-1) \Delta t, \quad(m=1,2,3 \ldots) \quad$ we integrate system (4) over $t$ in the interval $\left[0, t_{m}\right]$ and using the quadrature formula of the trapezoid we have

$$
\left\{\begin{array}{l}
C_{m}-\tilde{C}_{0}+\mu_{1} \sum_{i=1}^{m} A_{i} \frac{d C_{i}}{d x}+ \\
\quad+\mu_{2}(1-k) \sum_{i=1}^{m} A_{i}\left(C_{i}-N_{i}\right)=\sum_{i=1}^{m} A_{i} \frac{d^{2} C_{i}}{d x^{2}} \\
N_{m}-\bar{N}_{0}=\mu_{3} \sum_{i=1}^{m} A_{i}\left(C_{i}-N_{i}\right)
\end{array}\right.
$$


where $\Delta t$ is the time step, $A_{i}$ is the entire quadrature formula of the trapezoid.

After some transformations in (5), the following system of equations can be obtained

$$
\left\{\begin{array}{l}
\frac{d^{2} C_{m}}{d x^{2}}+a \frac{d C_{m}}{d x}+b C_{m}(x)=f_{m}(x) ; \\
N_{m}(x)=k_{6 m} A_{m}\left(\sum_{i=1}^{m-1} A_{i} C_{i}-\sum_{i=1}^{m-1} A_{i} N_{i}\right)+ \\
+k_{7 m}+k_{6 m} C_{m}(x),
\end{array}\right.
$$

where

$$
\begin{aligned}
& a=-\mu_{1} ; \quad b=-\mu_{2}\left(1-k+\frac{1}{\mu_{2} A_{m}}+\frac{\mu_{2}(1-k) \mu_{3} A_{m}}{1+\mu_{3} A_{m}}\right) ; \\
& k_{1 m}=-\frac{1}{A_{m}} ; k_{2 m}=\frac{\mu_{1}}{A_{m}} ; \\
& k_{3 m}=\frac{\mu_{3}(1-k)}{A_{m}}-\frac{\mu_{2}(1-k) \mu_{3}}{\left(1+\mu_{3} A_{m}\right)} ; k_{4 m}=-k_{3 m} ; \\
& k_{5 m}=-\frac{\tilde{N}_{0} \mu_{2}(1-k)}{\left(1+\mu_{3} A_{m}\right)}-\frac{1}{A_{m}} \tilde{C}_{0} ; k_{6 m}=\frac{\mu_{3} d t}{2\left(1+\mu_{3} A_{m}\right)} \text {; } \\
& k_{7 m}=\frac{\tilde{N}_{0}}{\left(1+\mu_{3} A_{m}\right)} \text {; } \\
& f_{m}(x)=k_{1 m} \sum_{i=1}^{m-1} A_{i} \frac{d^{2} C_{i}}{d x^{2}}+k_{2 m} \sum_{i=1}^{m-1} A_{i} \frac{d C_{i}}{d x}+ \\
& +k_{3 m} \sum_{i=1}^{m-1} A_{i} C_{i}+k_{4 m} \sum_{i=1}^{m-1} A_{i} N_{i}+k_{5 m} .
\end{aligned}
$$

The first equation of system (6) with boundary conditions

$$
\left\{\begin{array}{l}
C_{m}=C_{n} \text { at } x=0 ; \\
\frac{d C_{m}}{d x}=0 \text { at } x=1
\end{array}\right.
$$

is solved by the differential sweep method [10-13], according to which the solution is sought in the form:

$\alpha_{m}^{\prime}(x) C_{m}^{\prime}(x)+\beta_{m}(x) C_{m}(x)=\gamma_{m}(x)$

where $\alpha_{m}(x), \beta_{m}(x), \quad \gamma_{m}(x)$, are the sweep coefficients found from the solutions of the following Cauchy problem:

$$
\left\{\begin{array}{l}
\alpha_{m}^{\prime}(x)-a \cdot a_{m}(x)+\beta_{m}(x)=0 \\
\beta_{m}^{\prime}(x)-a_{m}(x) \cdot \beta_{m}(x)=0 \\
\gamma_{m}(x)=a_{m}(x) \cdot f_{m}(x)
\end{array}\right.
$$

$$
\left\{\begin{array}{l}
\alpha_{m}(0)=0 \\
\beta_{m}(0)=1 \\
\gamma_{m}(0)=C_{n}
\end{array}\right.
$$

Solving the Cauchy problem (7), (8) we find:

$$
C_{m}(1)=\frac{\gamma_{m}(1)}{\beta_{m}(1)} \text { and } C_{m}^{\prime}(1)=0
$$

Next, solving the equation

$$
\frac{d^{2} C_{m}}{d x^{2}}+a \frac{d C_{m}}{d x}+b C_{m}=f_{m}(x)
$$

under initial conditions (9), we find the salt content in the "through" pores $C_{m}(x)$ and substituting it in the second relation of system (6), determine the salt content in the "dead-end" pores $N_{m}(x)$.

The solution of the corresponding Cauchy problems can be carried out by the fourth-order Runge-Kutta method [14, 15].

\section{RESULTS}

Based on the above algorithm, a computer program was compiled, which is implemented as standard software in the algorithmic language $\mathrm{ABC}$ Pascal. Testing of a computer program that implements the algorithm of the proposed calculation method was carried out when solving the following problem:

$$
\begin{gathered}
\frac{\partial C}{\partial t}=3 \frac{\partial^{2} C}{\partial x^{2}}+\frac{\partial C}{\partial x}-0,5 C-4(x+2) e^{-0,5 t} \\
C=2 x^{2}-4 x+3 \quad \text { at } \quad t=0 \\
\begin{cases}C+0,75 \cdot \frac{\partial C}{\partial x}=0 & \text { at } x=0 \\
\frac{\partial C}{\partial x}=0 & \text { at } x=1,\end{cases}
\end{gathered}
$$

which has an exact solution:

$$
C(x, t)=\left(2 x^{2}-4 x+3\right) e^{-0,5 t} .
$$

The calculation results are shown in table 1 , where the numerical values of the solutions obtained by the proposed method are compared with the exact solution at different time intervals with show a good agreement. 
Table 1: Comparison of results obtained with exact solution

\begin{tabular}{|c|c|c|c|c|}
\hline \multirow[b]{2}{*}{$\mathbf{x}$} & \multicolumn{2}{|c|}{$t=3$} & \multicolumn{2}{|c|}{$t=5$} \\
\hline & $\begin{array}{c}\text { Exact } \\
\text { solution }\end{array}$ & $\begin{array}{l}\text { Approx. } \\
\text { solution }\end{array}$ & $\begin{array}{c}\text { Exact } \\
\text { solution }\end{array}$ & $\begin{array}{l}\text { Approx. } \\
\text { solution }\end{array}$ \\
\hline 0 & 0.66939 & 0.66930 & 0.24625 & 0.24618 \\
\hline 0.1 & 0.58460 & 0.58454 & 0.21506 & 0.21511 \\
\hline 0.2 & 0.50873 & 0.50865 & 0.18715 & 0.18708 \\
\hline 0.3 & 0.44179 & 0.44168 & 0.16252 & 0.16247 \\
\hline 0.4 & 0.38378 & 0.38369 & 0.14118 & 0.14108 \\
\hline 0.5 & 0.33469 & 0.33457 & 0.12312 & 0.12309 \\
\hline 0.6 & 0.29453 & 0.29449 & 0.10835 & 0.10827 \\
\hline 0.7 & 0.26329 & 0.26321 & 0.09686 & 0.09677 \\
\hline 0.8 & 0.24098 & 0.24088 & 0.08865 & 0.08856 \\
\hline 0.9 & 0.22759 & 0.22748 & 0.08372 & 0.08366 \\
\hline 1.0 & 0.22313 & 0.22305 & 0.08208 & 0.08195 \\
\hline
\end{tabular}

Table 2: Comparison of results obtained with exact solution

\begin{tabular}{|l|l|l|}
\hline \multirow{2}{*}{$\mathbf{x}$} & \multicolumn{2}{|c|}{$\boldsymbol{t}=\mathbf{8}$} \\
\cline { 2 - 3 } & \multicolumn{1}{|c|}{ Exact solution } & Approximate solution \\
\hline 0 & 0.05495 & 0.05484 \\
\hline 0.1 & 0.04799 & 0.04771 \\
\hline 0.2 & 0.04176 & 0.04161 \\
\hline 0.3 & 0.03626 & 0.03619 \\
\hline 0.4 & 0.03150 & 0.03144 \\
\hline 0.5 & 0.02748 & 0.02736 \\
\hline 0.6 & 0.02418 & 0.02409 \\
\hline 0.7 & 0.02161 & 0.02148 \\
\hline 0.8 & 0.01978 & 0.01961 \\
\hline 0.9 & 0.01868 & 0.01848 \\
\hline 1.0 & 0.01832 & 0.01811 \\
\hline
\end{tabular}

Figures 1 - 2 show the results of numerical calculations performed on a computer.

As seen from the computer experiments over time, the salt content decreases linearly (figure 1). Especially this can be observed in curve 3 of figure 1 .

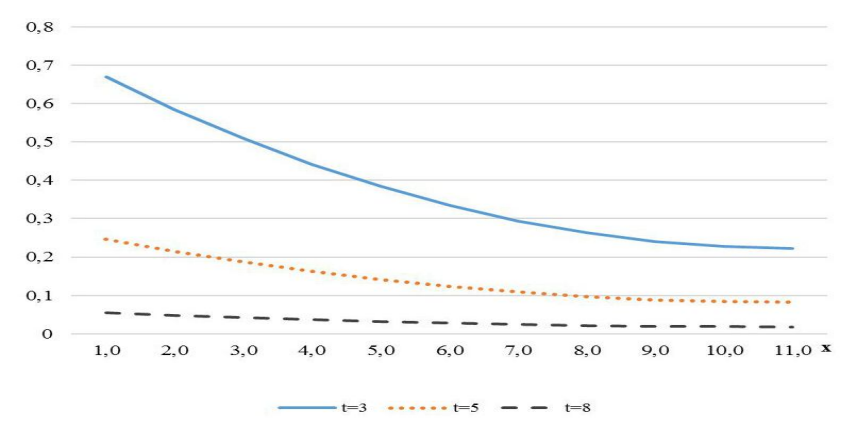

Figure 1: Change in salt content in the "through" pores at different values of filtration process

The change in salt content in the pores along the layer thickness is shown in figure 2 . As can be seen from figure 2, the salt content in the higher layers of soil is greater than in the lower layers, with time this difference noticeably decreases.

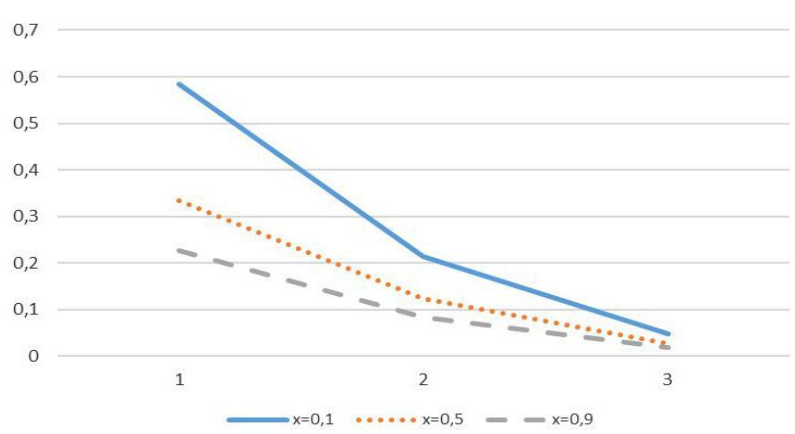

Figure 2: Change in salt content along the layer thickness

An analysis of numerical calculations showed that the salt content in the "dead end" and "through" pores changes both with time and with the thickness of soil layer (figures 1 - 2).

\section{CONCLUSION}

The results obtained show that the proposed numerical approach was effective for solving the problems of salt transfer in soils. Suggested computational algorithms, i.e. the method based on the use of quadrature formulas in combination with the differential sweep method, as well as the corresponding computer software made it possible to successfully carry out calculations to determine the solution content in "through" and "dead-end" pores of soil. The above approach to solving the problem can be extended to the problems of heat- and water-transfer in soils on ameliorated lands.

\section{ACKNOWLEDGEMENT}

The research was supported by Ministry of Innovative Development of the Republic of Uzbekistan (Grant No. BV-Atech-2018-9).

\section{REFERENCES}

1. N. Ravshanov, I. Khurramov, and S. Aminov. Mathematical modeling of the process of water-soline transport in soils, Journal of Physics: Conference Series, Vol. 1210, pp. 1-15, November, 2019.

2. A.A. Kashevarov. Modeling of water-drain and salt-transfer processes on swamped lands, Journal of Applied Mechanics and Technical Physics, Vol. 46, pp. 77-84, January 2005.

3. N. Ravshanov, and U. Saidov. Modelling technological process of ion-exchange filtration of fluids in porous media, Journal of Physics: Conference Series, Vol. 1015, pp. 1-8, May 2018.

4. N. Ravshanov, and Sh. Daliev. A mathematical model for predicting groundwater levels in two-layer 
formations, Information Technologies for Modeling and Control, Vol. 116, pp. 116-124, 2019.

5. N.N. Verigin. Some issues of chemical hydrodynamics of interest to land reclamation and hydraulic engineering, Moscow: Academy of Sciences of the USSR, 1953, pp. 1396-1382.

6. R.C.Mamat, A. Ramli, A.M. Samad, A. Kasa, S.F.M. Razali, M.B.H. Che Omar. Stability Assessment of Embankment on Soft Soil Improved with Prefabricated Vertical Drains Using Empirical and Limit Equilibrium Approaches, International Journal of Advanced Trends in Computer Science and Engineering, Vol. 8, pp. 444-449, 2019.

7. Thangadurai N., S.B. Vinay Kumar, and C. Prasanna Kumar. Fertilizer Optimization by an Smart Soil Analyzer with a Soil Tester for Agriculture Applications, International Journal of Advanced Trends in Computer Science and Engineering, Vol. 8, pp. 3628-3631, 2019.

8. A. Delgado, N. Rojas, J. Oblitas, B. Andres, A. Huerta, and Ch. Carbajal. Water Quality Assessment using the Grey Clustering Analysis on a river of Taxco, Mexico, International Journal of Advanced Trends in Computer Science and Engineering, Vol. 9, pp. 4717-4723, 2019.

9. M.H. Hamzah, A.M. Taib, S. Sharil, A.B. Ramli, and D.Z. Abang Hasbollah. The Stability of Diaphragm Wall for Deep Excavation, International Journal of Advanced Trends in Computer Science and Engineering, Vol. 8, pp. 303-309, 2019.

10. N. Ravshanov, Sh.K. Daliev, and O. Tagaev. Numerical simulation of two aquarius Horizons, International Journal of Advanced Trends in Computer Science and Engineering, Vol. 9, pp. 6549-6554, August 2020.

11. A. Ab Aziz, A.R. Zulkefli, and M.A. Khasim. Finite Different Method and Differential Quadrature Method for Solving Burgers Equation, International Journal of Advanced Trends in Computer Science and Engineering, Vol. 8, pp. 5-8, 2019.

12. N. Ravshanov, U.M. Saidov, and D.I. Mutin. Modelling of the technological process of multiple filtering suspensions with multi-layered filter, IOP Conference Series: Materials Science and Engineering, Vol. 537, April 2019.

13. N. Ravshanov, I.U. Shadmanov, and O.Ja. Kravets. Mathematical model for the study and prediction of a porous body thermal state, IOP Conference Series: Materials Science and Engineering, Vol. 537, pp. 1-8, April 2019.

14. S.K. Godunov. Equations of Mathematical Physics; Moscow: Science, 1971.

15. N.S. Bakhvalov. Numerical methods; Moscow: Science, 1975. 